\title{
Validating Reference Equations for Impulse Oscillometry in Healthy Mexican Children
}

\author{
Laura Gochicoa-Rangel MD MSc, Rodrigo del Río-Hidalgo MD, Juana Hernández-Ruiz MD, \\ Luis Rodríguez-Moreno MD, David Martínez-Briseño MSc, Uri Mora-Romero MD, \\ Silvia Cid-Juárez MD MSc, Cecilia García-Sancho MD MSc, and Luis Torre-Bouscoulet MD MSc
}

\begin{abstract}
BACKGROUND: The impulse oscillometry system (IOS) measures the impedance (Z) of the respiratory system, but proper interpretation of its results requires adequate reference values. The objectives of this work were: (1) to validate the reference equations for the IOS published previously by our group and (2) to compare the adjustment of new available reference equations for the IOS from different countries in a sample of healthy children. METHODS: Subjects were healthy 4-15$y$-old children from the metropolitan area of Mexico City, who performed an IOS test. The functional IOS parameters obtained were compared with the predicted values from 12 reference equations determined in studies of different ethnic groups. The validation methods applied were: analysis of the differences between measured and predicted values for each reference equation; correlation and concordance coefficients; adjustment by Z-score values; percentage of predicted value; and the percentage of patients below the lower limit of normality or above the upper limit of normality. RESULTS: Of the 224 participants, $117(52.3 \%)$ were girls, and the mean age was $8.6 \pm 2.3 \mathrm{y}$. The equations that showed the best adjustment for the different parameters were those from the studies by Nowowiejska et al (2008) and Gochicoa et al (2015). The equations proposed by Frei et al (2005), Hellinckx et al (1998), Kalhoff et al (2011), Klug and Bisgaard (1998), de Assumpção et al (2016), and Dencker et al (2006) overestimated the airway resistance of the children in our sample, whereas the equation of Amra et al (2008) underestimated it. In the analysis of the lower and upper limits of normality, Gochicoa et al equation was the closest, since $5 \%$ of subjects were below or above percentiles 5 and 95 , respectively. The study found that, in general, all of the equations showed greater error at the extremes of the age distribution. CONCLUSIONS: Because of the robust adjustment of the present study reference equations for the IOS, it can be recommended for both clinical and research purposes in our population. The differential adjustment of other equations underlines the need to obtain local reference values. Key words: oscillometry; pulmonary function test; reference values. [Respir Care 2017;62(9):1156-1165. (C) 2017 Daedalus Enterprises]
\end{abstract}

\section{Introduction}

An impulse oscillometry system (IOS) measures the impedance of the respiratory system $(\mathrm{Z})$ at different oscilla-

Drs Gochicoa-Rangel, del Río-Hidalgo, Hernández-Ruiz, Mora-Romero, Cid-Juárez, García-Sancho, and Torre-Bouscoulet are affiliated with the Departamento de Fisiología Respiratoria, Instituto Nacional de Enfermedades Respiratorias "Ismael Cosío Villegas", Mexico City, Mexico. Dr Rodríguez-Moreno is affiliated with the Laboratorio de Función Pulmonar, S de R.L., Mexico City, Mexico. Mr Martínez-Briseño is affiliated with the Departamento de Investigación en Epidemiología y Ciencias Sociales en Salud, Instituto Nacional de Enfermedades Respiratorias "Ismael Cosío Villegas", Mexico City, Mexico. tion frequencies. Based on $\mathrm{Z}_{\mathrm{RS}}$, we derived resistance $(\mathrm{R})$ and reactance $(\mathrm{X})$, the 2 forces that must be overcome for air to be displaced into, and out of, the respiratory system. ${ }^{1}$ The IOS has emerged recently as a useful clinical test; however, the adequate interpretation of a pulmonary function test depends on the availability of valid reference

The authors have disclosed no conflicts of interest.

Supplementary material related to this paper is available at http:// www.rcjournal.com. 
values, to compare the results of patients, according to height, age, sex, and ethnic group. ${ }^{2,3}$

Reference values are generated from an equation that must be validated in a healthy population distinct from the one in which it was built. ${ }^{4}$ The closer the difference between the value predicted by the equation and the value measured in healthy subjects approaches zero, the better the adjustment of the equation. In 2015, we published IOS reference values for children, but the equation has not been properly validated. 5 Thus, the objective of this study was to validate the IOS reference equation published by our group and to compare its adjustment with those of other IOS reference equations published for children. ${ }^{5-16}$ The hypothesis is that the Gochicoa et $\mathrm{al}^{5}$ reference equation will show minimal error in predicting IOS values for a pediatric population, whereas other IOS reference equations for different populations of healthy children will produce differential adjustments.

\section{Methods}

This was a cross-sectional study approved by the Committee for Science and Bioethics in Research at the National Institute for Respiratory Diseases, "Ismael Cosío Villegas" (code C20-11) in Mexico City. Healthy children age 4-15 y from the metropolitan area of Mexico City were recruited from among alumni attending kindergartens and primary or secondary schools during 2014-2015. The same health questionnaire used to recruit children and adolescents used in 2011-2012 for the IOS reference equation was sent to parents, and those who agreed to participate signed the informed consent. Children who fulfilled the following inclusion criteria were included: (1) without chronic illnesses, including heart, liver, kidney, and respiratory (asthma, wheezing, rhinosinusitis) diseases; (2) without history of prematurity, pneumonia, bronchiolitis, or regular exposure to environmental tobacco or biomass smoke; (3) absence of any acute respiratory morbidity in the past $15 \mathrm{~d}$; (4) without suspicion of sleep apnea/hypopnea syndrome or gastroesophageal reflux. The inclusion criteria were the same as those applied in the reference equation study. Two anthropometric measurements were taken: height in centimeters (model 206 wall-mounted stadiometer, SECA, Hamburg, Germany), and weight in ki-

\footnotetext{
Dr Gochicoa-Rangel presented a version of this work at the Annual Meeting of the Mexican Thoracic Society, held in April 6-10, 2015, in Puerto Vallarta, México.
}

Correspondence: Luis Torre-Bouscoulet MD, Calzada de Tlalpan 4502, Col. Sección XVI, CP 14080 D.F., México. E-mail: luistorreb@gmail.com.

DOI: $10.4187 /$ respcare.05247

\section{QUICK LOOK}

\section{Current knowledge}

Impulse oscillometry has emerged recently as a useful clinical test; however, the adequate interpretation of results depends on the availability of valid reference values. Although several equations from different countries have been published, little is known about their adjustment in healthy children.

\section{What this paper contributes to our knowledge}

We demonstrated a robust adjustment of the Gochicoa et $\mathrm{l}^{5}$ IOS reference equation, which allows us to recommend it for both clinical and research purposes in similar populations. The validation of IOS reference equations in this study could contribute to a better clinical interpretation of IOS results.

lograms (precision scale; model 813, SECA). Then each child performed at least 3 IOS maneuvers that were acceptable and repeatable according to international recommendations. ${ }^{3,17,18}$ The means of the 3 valid maneuvers from each child were used for the analyses. All IOS measurements $(\mathrm{Z}, \mathrm{R}, \mathrm{X}$, resonant frequency, and reactance area) were performed with an IOS device (Master ScreenIOS, CareFusion, San Diego, California), calibrated daily for volume and flow and checked for pressure. To find other IOS reference equations for children, a search in PubMed using the key words oscillometry, pulmonary function test, and reference values was performed during 2015. Table E1 (see the supplementary materials at http://www.rcjournal.com) summarizes the characteristics of the studies identified. ${ }^{5-16}$

To analyze the adjustment of the reference equations, the predicted value for each IOS parameter from each equation found was obtained. The concordance analysis between the predicted values from equations published by different authors and the measured values from the healthy children were done according to the Bland-Altman method. ${ }^{19}$ The predicted value was then subtracted from the value measured for each subject to determine the "error."

The mean and SE of those differences were obtained. We considered that the smaller the difference between the measured and predicted value, the better the adjustment. Adjustment was also evaluated by the $\mathrm{Z}$ score for each variable and was considered a good fit when mean $\pm \mathrm{SD}$ values were $0 .{ }^{20}$ Not all equations report reference values for all possible resistances or reactances, so the comparisons were performed only with the available values. To determine whether these adjustments were homogeneous with respect to sex, height, 
VALIDATING IMPULSE OSCILLOMETRY EQUATIONS

Table 1. Anthropometric Characteristics and Impulse Oscillometry Measurement Values

\begin{tabular}{|c|c|c|c|}
\hline Characteristics & All $(N=224)$ & Female $(n=117)$ & Male $(n=107)$ \\
\hline Age, y & $8.6(6.1-10.5)$ & $8.8(6.4-10.5)$ & $8.6(6-10.3)$ \\
\hline Weight, $\mathrm{kg}$ & $28.4(21.4-37.3)$ & $28.5(21.7-38.7)$ & $28.1(21.3-36.5)$ \\
\hline Height, $\mathrm{cm}$ & $129(115-139)$ & $129(115-142)$ & $129(115-137)$ \\
\hline BMI, $\mathrm{kg} / \mathrm{m}^{2}$ & $16.8(15.3-19.6)$ & $17.1(15.4-19.5)$ & $16.5(15.2-19.8)$ \\
\hline BMI, Z score & $0.5(-0.2$ to 1.3$)$ & $0.6(-0.2$ to 1.3$)$ & $0.5(-0.3$ to 1.4$)$ \\
\hline $\mathrm{Z} 5 \mathrm{~Hz}, \mathrm{kPa} / \mathrm{L} / \mathrm{s}$ & $0.71(0.58-0.87)$ & $0.7(0.58-0.88)$ & $0.71(0.57-0.86)$ \\
\hline R $5 \mathrm{~Hz}, \mathrm{kPa} / \mathrm{L} / \mathrm{s}$ & $0.67(0.55-0.81)$ & $0.66(0.55-0.83)$ & $0.67(0.55-0.81)$ \\
\hline $\mathrm{R} 10 \mathrm{~Hz}, \mathrm{kPa} / \mathrm{L} / \mathrm{s}$ & $0.57(0.45-0.69)$ & $0.56(0.45-0.69)$ & $0.59(0.47-0.68)$ \\
\hline R $15 \mathrm{~Hz}, \mathrm{kPa} / \mathrm{L} / \mathrm{s}$ & $0.52(0.42-0.64)$ & $0.52(0.42-0.64)$ & $0.52(0.42-0.62)$ \\
\hline $\mathrm{R} 20 \mathrm{~Hz}, \mathrm{kPa} / \mathrm{L} / \mathrm{s}$ & $0.48(0.39-0.6)$ & $0.5(0.41-0.6)$ & $0.48(0.38-0.59)$ \\
\hline X $5 \mathrm{~Hz}, \mathrm{kPa} / \mathrm{L} / \mathrm{s}$ & $-0.23(-0.29$ to 0.19$)$ & $-0.24(-0.3$ to 0.19$)$ & $-0.22(-0.29$ to 0.19$)$ \\
\hline X $10 \mathrm{~Hz}, \mathrm{kPa} / \mathrm{L} / \mathrm{s}$ & $-0.12(-0.15$ to 0.08$)$ & $-0.12(-0.15$ to 0.08$)$ & $-0.12(-0.15$ to 0.08$)$ \\
\hline X $15 \mathrm{~Hz}, \mathrm{kPa} / \mathrm{L} / \mathrm{s}$ & $-0.07(-0.11$ to 0.04$)$ & $-0.07(-0.1$ to 0.03$)$ & -0.07 ( -0.11 to 0.05$)$ \\
\hline X $20 \mathrm{~Hz}, \mathrm{kPa} / \mathrm{L} / \mathrm{s}$ & $-0.02(-0.05$ to 0.01$)$ & $-0.02(-0.05$ to 0.01$)$ & $-0.02(-0.05$ to 0.01$)$ \\
\hline $\mathrm{AX}, \mathrm{L} / \mathrm{s}$ & $1.57(1.06-2.19)$ & $1.58(1.03-2.21)$ & $1.56(1.12-2.14)$ \\
\hline $\mathrm{f}^{\mathrm{res}}, \mathrm{Hz}$ & $21.25(18.75-23.4)$ & $21.59(18.66-23.7)$ & $21.12(18.94-23.23)$ \\
\hline $\begin{array}{l}\text { Results are median (inter } \\
B M I=\text { body mass index } \\
Z=\text { impedance of respira } \\
R=\text { resistance of the res } \\
X=\text { reactance of the res } \\
A X=\text { reactance area } \\
\mathrm{f}_{\text {res }}=\text { resonant frequency }\end{array}$ & not significant differences betw & & \\
\hline
\end{tabular}

and age, predicted values for each equation by sex were calculated and plotted as a function of height. This analysis was conducted with the Stata 13.1 statistical package (StataCorp, College Station, Texas) with significance set at a value of $P<.05$.

\section{Results}

Two hundred twenty-four participants (117 [52.3\%] girls) were included, and their mean age was $8.6 \pm 2.3 \mathrm{y}$. Table 1 shows the general characteristics and IOS measurement values of the study population. No significant differences in anthropometry and IOS variables, according to sex, were found. Table 2 presents the concordance analysis between the predicted values from equations published by different authors and the measured values obtained from healthy children in the present study. The highest concordance for resistances was obtained from the Dencker et al, ${ }^{9}$ Nowowiejska et al, ${ }^{15}$ and Gochicoa et al ${ }^{5}$ equations, and the highest concordance for the reactance was obtained from the same authors and Frei et $\mathrm{al}^{10}$ equation.

Figures 1, 2 and 3 show the errors calculated between the measured and predicted values in absolute terms (Fig. 1), as Z-score values (Fig. 2, A and B), and as percentages of predicted values (Fig. 3). Because not all of the studies (Hellinckx et al, ${ }^{11}$ Klug and Bisgaard, ${ }^{7}$ Kalhoff et $\mathrm{al}^{6}$ ) reported SE, we were unable to obtain Z-score values, upper limit of normality, and lower limit of normality for every variable. Reactances as a percentage of predicted show high variability (Fig. 3, A and B). In the supplemental material, we describe the mean $\pm \mathrm{SD}$ of each variable as percentage of predicted value and as Z-score values (supplementary Tables E2 and E3). Significant differences in $\mathrm{SD}$ in the percentages of predicted values and $\mathrm{Z}$ scores were found with the different reference equations (supplementary Tables E4 and E5). Therefore, the mean value and the dispersion could change with each equation.

The adjustment of the equations differed in relation to the height of the subjects and the specific parameter evaluated, although 2 equations (Dencker et $\mathrm{al}^{9}$ and Frei et $\mathrm{al}^{10}$ ) showed good adjustment in the shortest children in resistances and reactances, mainly at low frequencies. Sex did not affect the adjustment of the equations.

To explore the effect of ethnicity, correlation analysis between predicted values from Nowowiejska et al ${ }^{15}$ (European population) and Gochicoa et $\mathrm{al}^{5}$ (Latino population) were performed, which generated correlation coefficients that ranged from 0.96 to 0.98 (Fig. 4); but when the limits of normality were analyzed, we found that the Gochicoa et $\mathrm{al}^{5}$ equation produced from 6 to $9 \%$ of observations above or below the limits of normality, a little above the $5 \%$ that was expected. In contrast, all of the other equations from Nowowiejska et al ${ }^{15}$ generated results in which $>20 \%$ of subjects fell outside the limit of normality at one extreme and nearly $0 \%$ at the other. These findings clearly 






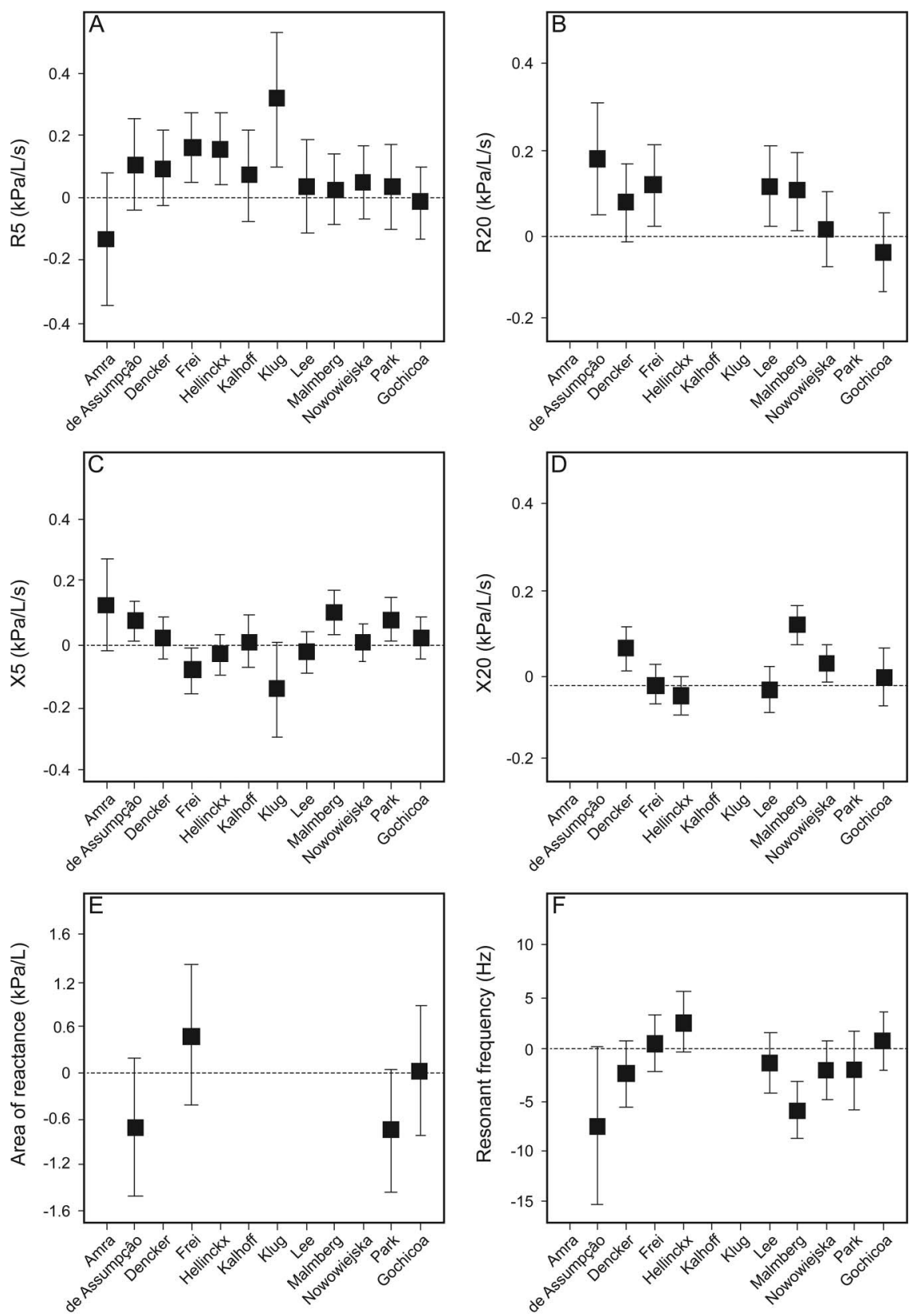

Fig. 1. Mean and SD of differences (error) for each equation reported by the different authors, for respiratory system resistance (R), respiratory system reactance $(X)$, area of reactance, and resonant frequency. Differences for each equation were calculated by subtracting the measured value from the predicted value. An equation with ideal adjustment will have a null difference between the observed and expected values. $\mathrm{R} 5=$ $\mathrm{R}$ measured at $5 \mathrm{~Hz} ; \mathrm{R} 20=\mathrm{R}$ measured at $20 \mathrm{~Hz} ; \mathrm{X} 5=\mathrm{X}$ measured at $5 \mathrm{~Hz} ; \mathrm{X} 20=\mathrm{X}$ measured at $20 \mathrm{~Hz}$.

demonstrate an inadequate adjustment for the other reference equations (Table 3).

\section{Discussion}

The present study results suggest that the IOS equations published recently by Gochicoa et $\mathrm{al}^{5}$ had the highest goodness of fit in this sample, followed by the Nowowiejska et al equation. ${ }^{15}$ (For other populations, it must be corroborated that the equation presents the best fit.)

We believe that the process of validating IOS reference equations is important because of the growing number of publications that demonstrate the usefulness of the IOS for clinical medicine and because correct interpretations of this test depend on the availability of a reference equation with a robust adjustment. It has been proposed that the 
A
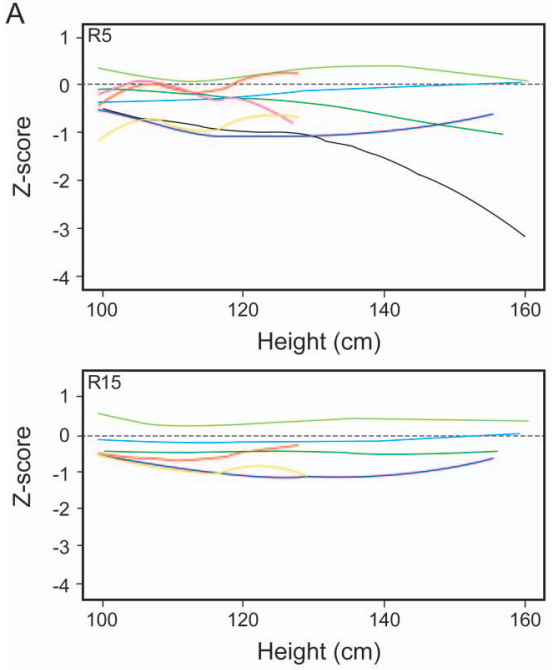

de Assumpçâo Malmberg

B
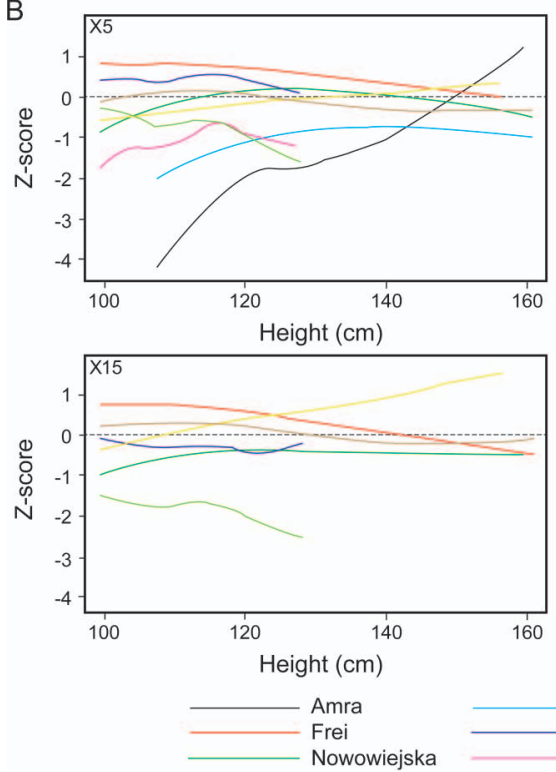
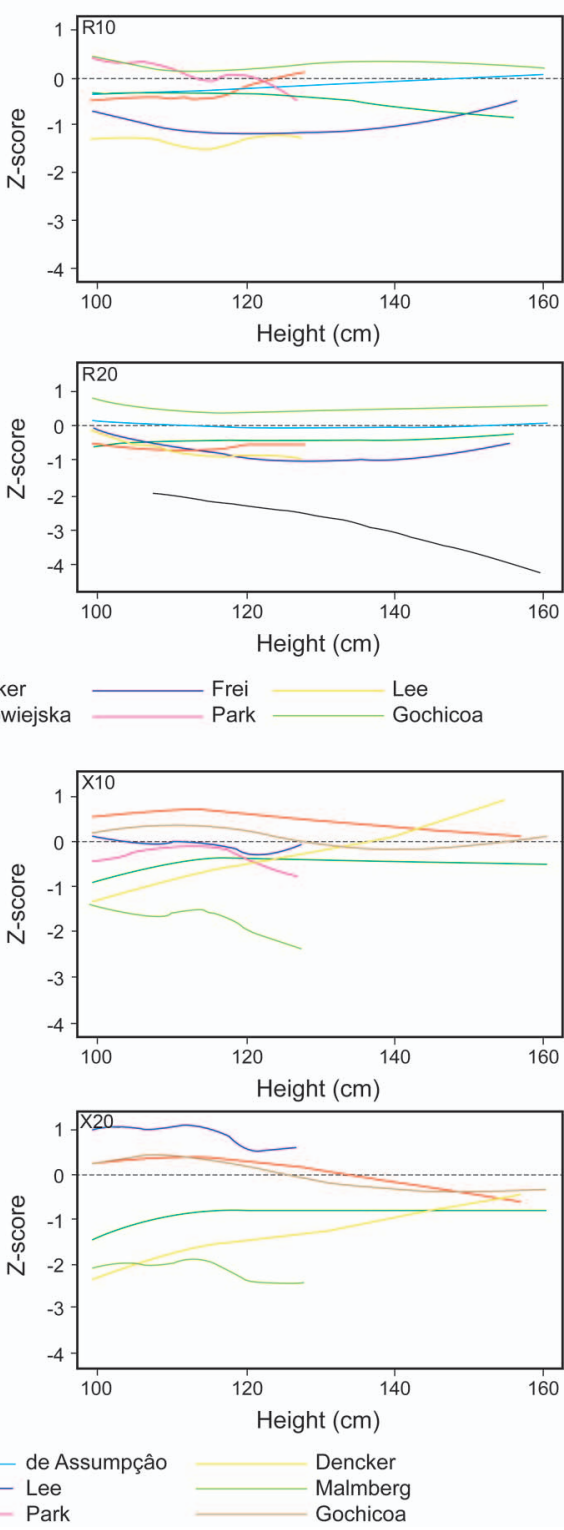

Fig. 2. Impulse oscillometry values as $Z$ scores for each resistance $(A)$ and reactance $(B)$ and for each equation evaluated. The $A m r a$ et al ${ }^{8}$ equation was not plotted at R5, R15, or X5 because its $Z$ value is so large that the other equations would not be appreciated in the graph. The Hellinckx et al, ${ }^{11}$ Kalhoff et al, ${ }^{6}$ and Klug and Bisgaard ${ }^{7}$ equations are not included because they do not report the SE, so the Z-score value can not be calculated. The lines of regression from the other studies are not shown because they do not have an equation to calculate this value or because they did not report the SD of the residuals that would have permitted making that calculation. $\mathrm{R}=$ respiratory system resistance, followed by the frequency at which it was measured $(5,10,15$, or $20 \mathrm{~Hz}) . \mathrm{X}=$ respiratory system reactance, followed by the frequency at which it was measured $(5,10,15$, or $20 \mathrm{~Hz})$.

observed differences between prediction equations can be due to technical and procedural differences, true (biological) differences between populations, and smaller samples that can have greater dispersion of data. ${ }^{21}$

The most common clinical applications of an IOS are for cases of chronic pulmonary diseases, such as asthma, ${ }^{11,12,22}$ bronchopulmonary dysplasia, ${ }^{23}$ neuromuscular diseases, ${ }^{24}$ and cystic fibrosis. ${ }^{25}$ Moreover, cutoff values have recently been proposed that should be taken into account before interpret- ing responses to bronchodilators as positive. ${ }^{26}$ Indeed, the IOS has even been suggested as a bronchial challenge test. ${ }^{27}$

This study analyzed the adjustment of IOS reference equations determined in studies performed in several countries, all of which used the same measuring equipment (Master Screen-IOS). To analyze the adjustment of the equations and substantiate the validation process, different methods were applied: analysis of the differences between the predicted and measured values for 


\section{VALIDATING IMPUlse Oscillometry EQuations}

A
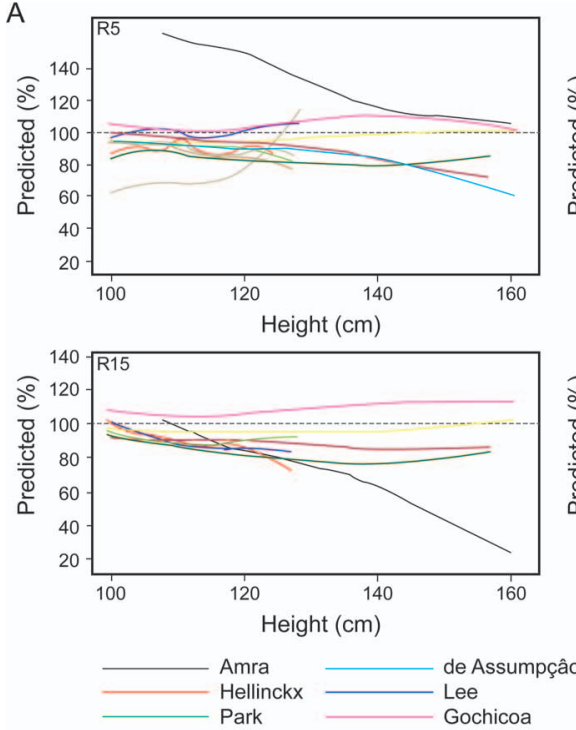

B
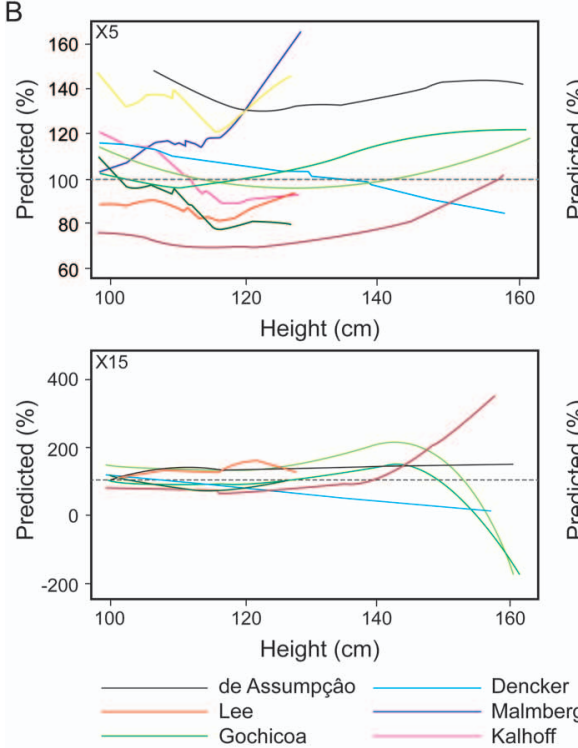
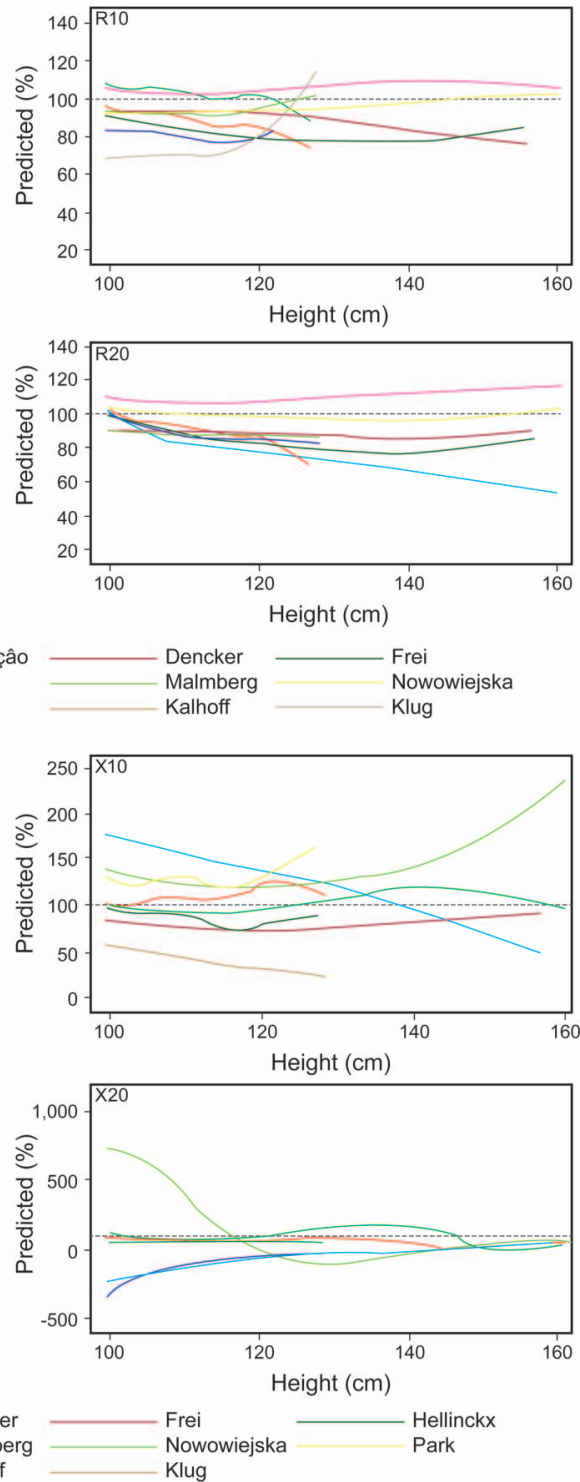

Fig. 3. Impulse oscillometry parameters expressed as the percentage of the predicted value for each resistance $(A)$ and reactance $(B)$ and for each equation evaluated. The Amra et al ${ }^{8}$ equation was not plotted at X15 because its percentage of predicted is so large that the other equations would not be appreciated on the graph. This also occurred with the Malmberg et al ${ }^{14}$ equation at X10 and X20. The lines of regression are not shown for the other studies because they do not have an equation to calculate this value. $\mathrm{R}=$ respiratory system resistance, followed by the frequency at which it was measured $(5,10,15$, or $20 \mathrm{~Hz}) . \mathrm{X}=$ respiratory system reactance, followed by the frequency at which it was measured $(5,10,15$, or $20 \mathrm{~Hz})$.

each reference equation; correlation and concordance coefficients; adjustment by Z-score values; percentage of predicted value; and the percentages of subjects that registered above or below the upper and lower limits of normality, respectively. This approach allowed us to not only verify whether the equations had good adjustment, but also to detect whether, when applied to the study population, they generated high rates of false positives or negatives, based on the principle that if adjustment is adequate, approximately $5 \%$ of healthy individuals will fall outside the limit of normality (ie, the fifth percentile).

The equations in Frei et al, ${ }^{10}$ Hellinckx et al, ${ }^{11}$ de Assumpção et $\mathrm{al}^{13}$ and Dencker et $\mathrm{al}^{9}$ (the latter mainly in older children) overestimated resistances, thus producing a significant percentage of false negatives. The Amra et al ${ }^{8}$ equation, in contrast, underestimated resistances and thus generated a significant percentage of false positives. The equations that showed the best adjustment were those in Gochicoa et $\mathrm{al}^{5}$ and Nowowiejska et al, ${ }^{15}$ although the 


\section{VALIDATING Impulse Oscillometry Equations}


Fig. 4. Association between Nowowiejska et $\mathrm{al}^{15}$ and Gochicoa et al. ${ }^{5}$ Lines correspond to the concordance between these 2 equations. As can be seen, the association is good, but the degree of agreement between them is not. $\mathrm{R}=$ respiratory system resistance, followed by the frequency at which it was measured $(5$ or $20 \mathrm{~Hz})$. X = respiratory system reactance, followed by the frequency at which it was measured $(5 \mathrm{~Hz})$. Respiratory system resistance and reactance are expressed in $\mathrm{kPa} / \mathrm{L} / \mathrm{s}$. Resonant frequency is expressed in $\mathrm{Hz}$.

Table 3. Percentage of Participants Above or Below the Limit of Normality According to the Different Reference Equations

\begin{tabular}{|c|c|c|c|c|c|c|c|c|c|}
\hline & $\begin{array}{l}\text { Amra } \\
\text { et } \mathrm{al}^{8}\end{array}$ & $\begin{array}{l}\text { Dencker } \\
\text { et } \mathrm{al}^{9}\end{array}$ & $\begin{array}{l}\text { Frei } \\
\text { et } \mathrm{al}^{10}\end{array}$ & $\begin{array}{l}\text { Lee } \\
\text { et } \mathrm{al}^{12}\end{array}$ & $\begin{array}{l}\text { de Assumpção } \\
\text { et } \mathrm{al}^{13}\end{array}$ & $\begin{array}{l}\text { Malmberg } \\
\text { et } \mathrm{al}^{14}\end{array}$ & $\begin{array}{c}\text { Nowowiejska } \\
\text { et al }{ }^{15}\end{array}$ & $\begin{array}{l}\text { Park } \\
\text { et } \mathrm{al}^{16}\end{array}$ & $\begin{array}{c}\text { Gochicoa } \\
\text { et } \mathrm{al}^{5}\end{array}$ \\
\hline $\mathrm{R}(5 \mathrm{~Hz})^{*}$ & 61.8 & 0.6 & 0.6 & 1.2 & 4.7 & 2.4 & 0.5 & 4.3 & 6.5 \\
\hline $\mathrm{R}(10 \mathrm{~Hz})^{*}$ & NA & 0.6 & 0.6 & 1.2 & NA & 1.2 & 0.5 & 2.2 & 6.9 \\
\hline $\mathrm{R}(15 \mathrm{~Hz})^{*}$ & 24.7 & 0 & 0.6 & 1.2 & NA & 0 & 0 & NA & 8.3 \\
\hline $\mathrm{R}(20 \mathrm{~Hz})^{*}$ & NA & 0 & 0 & 0 & 0 & 0 & 0 & NA & 9.7 \\
\hline $\mathrm{X}(5 \mathrm{~Hz}) \dagger$ & 54.7 & 2.8 & 0 & 0 & 16.5 & 18.2 & 5.6 & 0 & 4.6 \\
\hline $\mathrm{X}(10 \mathrm{~Hz}) \dagger$ & NA & 5.6 & 0 & 2.4 & NA & 47.5 & 9.3 & 2.2 & 3.2 \\
\hline $\mathrm{X}(15 \mathrm{~Hz}) \dagger$ & 100 & 1.1 & 0.6 & 3.7 & NA & 50.0 & 8.3 & NA & 2.8 \\
\hline $\mathrm{X}(20 \mathrm{~Hz}) \dagger$ & NA & 33.3 & 0.6 & 1.2 & NA & 100 & 13.4 & NA & 3.7 \\
\hline $\mathrm{AX}^{*}$ & NA & NA & 0.6 & NA & 61 & NA & NA & 19.6 & 2.8 \\
\hline $\mathrm{f}_{\mathrm{res}} *$ & NA & 31.7 & 8.9 & 19.5 & 60.8 & 0 & 83.3 & 10.9 & 7.9 \\
\hline
\end{tabular}

Values are percentages. The equations of Hellinckx et al ${ }^{10}$, Kalhoff et al, ${ }^{5}$ and Klug and Bisgaard ${ }^{6}$ are not included because they do not report the SE.

* Upper limit of normality.

$\dagger$ Lower limit of normality.

$\mathrm{R}=$ respiratory system resistance

$\mathrm{X}=$ respiratory system reactance

$\mathrm{AX}=$ reactance area

$\mathrm{f}_{\text {res }}=$ resonant frequency

$\mathrm{NA}=$ not available

latter could generate a high rate of false negatives because at resistances of 5 and $10 \mathrm{~Hz}$, only $0.5 \%$ of the children tested fell outside the limit, whereas at 15 and $20 \mathrm{~Hz}$, no subject registered a result below the lower limit of normality.

Several authors found that height, a general indicator of body size, is the main determinant of pulmonary resistances. ${ }^{10,11,14-16}$ Similar to Amra et al, ${ }^{8}$ Lee et al, ${ }^{12}$ and de Assumpção et $\mathrm{al}^{13}$ we found that age is an adequate independent predictor of resistance (ie, individuals of different ages but the same height will produce different measurements). The studies by Gochicoa et al, ${ }^{5}$ Amra et al, ${ }^{8}$ and Nowowiejska et al ${ }^{15}$ included preschool-age, school-age, and adolescent subjects. This 
broad age range made it possible, even in a cross-sectional study, to analyze how resistances and reactances are modified during a period of growth and development. There is some controversy surrounding the participation of sex as a determinant of resistances. Duiverman et $\mathrm{al}^{28}$ reported that boys age 8 y had greater resistance than girls, but others ${ }^{5,8-13,15,16,29}$ found greater resistance in females, especially school-age and adolescent girls. These latter results concur with the studies by Aarli et $\mathrm{al}^{30}$ and Newbury et al, ${ }^{31}$ who determined that airway resistance is greater in women than in men during adulthood.

The finding that the best adjustments were for the equations proposed by Gochicoa et $\mathrm{al}^{5}$ and Nowowiejska et $\mathrm{al}^{15}$ appears to be related to the following conditions: (1) they were formulated on the basis of a population with a wider age range; (2) they took sex into account when predicting resistances; and (3) the equations they developed were of a non-linear type. The differences observed in the adjustment of the different equations agree with those reported in spirometry studies, ${ }^{32}$ where both ethnic and sex components contributed significantly to the models. Spirometry studies have shown that children living in Mexico City have greater pulmonary volumes than children of the same size, sex, and age in various other countries, a phenomenon also seen in adult populations. It has yet to be determined, however, whether the greater forced vital capacity associated with elevation above sea level may substantially modify predictive models for IOS parameters. The poor adjustment of the equations in de Assumpção et al ${ }^{13}$ drew our attention because, although they considered both age and size as predictors of resistance and were generated in a study of a group of Latin American subjects, they predict a higher value than the one determined for our population. One possible explanation of this difference is that the respective studies involved (1) groups of distinct ethnic origin and (2) subjects with distinct anthropometric characteristics.

This study has some limitations, primarily the size of the sample of healthy children and the fact that it was not population-based. Quanjer et $\mathrm{al}^{21}$ emphasized that for a reference equation to be validated, in respiratory function tests (specifically spirometry), at least 300 subjects (150 men, 150 women) must be included. This contrasts with the present study, which has gathered 224 subjects $(76 \%$ of the ideal number). However, the suggestion of Quanjer et $\mathrm{al}^{21}$ was made to evaluate an equation that encompasses a very broad age range (2.5-95 y), in which different growth stages are included (children's growth and pulmonary development as well as subsequent physiological decline of respiratory function), unlike the present study, which encompasses a less extensive range (4-14 y) with fewer physiological changes. Thus, we propose that the number of subjects is sufficient to evaluate the adjustment of the different equations, generated in a similar age range. Whereas these factors could limit the external validity of our results, a strength of the present study is that all IOS tests were performed with the same commercial equipment used to generate the equation. Also, the equipment was calibrated daily to verify volume and pressure, and the linearity of the sensor was evaluated weekly in accordance with international recommendations, ${ }^{33}$ and all IOS maneuvers were performed in a standardized manner.

\section{Conclusions}

The robust adjustment of the Gochicoa et al ${ }^{5}$ IOS reference equation justifies recommending it for both clinical and research purposes. The differential adjustments of the other equations emphasize the need to obtain local reference values. These results coincide with the statistical indication that the ideal way to determine reference values for some biological measurements is to study a sample group with a profile that is generally similar to that of the population to which the equation will be applied.

\section{REFERENCES}

1. Al-Mutairi SS, Sharma PN, Al-Alawi A, Al-Deen JS. Impulse oscillometry: an alternative modality to the conventional pulmonary function test to categorise obstructive pulmonary disorders. Clin Exp Med 2007;7(2):56-64.

2. Pellegrino R, Viegi G, Brusasco V, Crapo RO, Burgos F, Casaburi $\mathrm{R}$, et al. Interpretative strategies for lung function tests. Eur Respir J 2005;26(5):948-968.

3. Beydon N, Davis SD, Lombardi E, Allen JL, Arets HG, Aurora P, et al. An official American Thoracic Society/European Respiratory Society statement: pulmonary function testing in preschool children. Am J Respir Crit Care Med 2007;175(12):1304-1345.

4. Stanojevic S, Wade A, Lum S, Stocks J. Reference equations for pulmonary function tests in preschool children: a review. Pediatr Pulmonol 2007;42(10):962-972.

5. Gochicoa-Rangel L, Torre-Bouscoulet L, Martínez-Briseño D, Rodríguez-Moreno L, Cantú-González G, Vargas MH. Values of impulse oscillometry in healthy Mexican children and adolescents. Respir Care 2015;60(1):119-127.

6. Kalhoff H, Breidenbach R, Smith HJ, Marek W. Impulse oscillometry in preschool children and association with body mass index. Respirology 2011;16(1):174-179.

7. Klug B, Bisgaard H. Specific airway resistance, interrupter resistance, and respiratory impedance in healthy children aged 2-7 years. Pediatr Pulmonol 1998;25(5):322-331.

8. Amra B, Soltaninejad F, Golshan M. Respiratory resistance by impulse oscillometry in healthy Iranian children aged 5-19 years. Iran J Allergy Asthma Immunol 2008;7(1):25-29.

9. Dencker M, Malmberg LP, Valind S, Thorsson O, Karlsson MK, Pelkonen A, et al. Reference values for respiratory system impedance by using impulse oscillometry in children aged 2-11 years. Clin Physiol Funct Imaging 2006;26(4):247-250.

10. Frei J, Jutla J, Kramer G. Reference values in children 100 to $150 \mathrm{~cm}$ in height and 3 to 10 years of age. Chest 2005;128(3):1266-1273.

11. Hellinckx J, De Boeck K, Bande-Knops J, van der Poel M, Demedts M. Bronchodilator response in 3-6.5 years old healthy and stable asthmatic children. Eur Respir J 1998;12(2):438-443. 


\section{VALIDATING IMPUlse OSCILLOMETRY EQUATIONS}

12. Lee JY, Seo JH, Kim HY, Jung YH, Kwon JW, Kim BJ, et al. Reference values of impulse oscillometry and its utility in the diagnosis of asthma in young Korean children. J Asthma 2012;49(8): 811-816.

13. de Assumpção MS, Gonçalves RM, Martins R, Bobbio TG, Schivinski CI. Reference equations for impulse oscillometry system parameters in healthy Brazilian children and adolescents. Respir Care 2016; 61(8):1090-1099.

14. Malmberg LP, Pelkonen A, Poussa T, Pohianpalo A, Haahtela T, Turpeinen M. Determinants of respiratory system input impedance and bronchodilator response in healthy Finnish preschool children. Clin Physiol Funct Imaging 2002;22(1):64-71.

15. Nowowiejska B, Tomalak W, Radliński J, Siergiejko G, Latawiec W, Kaczmarski M. Transient reference values for impulse oscillometry for children aged 3-18 years. Pediatr Pulmonol 2008;43(12): 1193-1197.

16. Park JH, Yoon JW, Shin YH, Jee HM, Wee YS, Chang SJ, et al. Reference values for respiratory system impedance using impulse oscillometry in healthy preschool children. Korean J Pediatr 2011; 54(2):64-68

17. Marchal F, Hall GL. Forced oscillation technique. Eur Respir Mon 2010;47:121-136

18. Oostveen E, MacLeod D, Lorino H, Farré R, Hantos Z, Desager K, et al. The forced oscillation technique in clinical practice: methodology, recommendations and future developments. Eur Respir J 2003; 22(6): 1026-1041.

19. Bland JM, Altman DG. Statistical methods for assessing agreement between two methods of clinical measurement. Lancet 1986;1(8476): 307-310.

20. Kirkwood BR, Sterne J, editors. Transformations. In: Essential medical statistics. Malden, Massachusetts: Wiley-Blackwell; 2003:117127.

21. Quanjer PH, Stocks J, Cole TJ, Hall GL, Stanojevic S, Global Lungs Initiative. Influence of secular trends and sample size on reference equations for lung function tests. Eur Respir J 2011;37(3):658-664.

22. Manoharan A, von Wilamowitz-Moellendorff A, Morrison A, Lipworth BJ. Effects of formoterol or salmeterol on impulse oscillometry in patients with persistent asthma. J Allergy Clin Immunol 2016; 137(3):727-733.e1.
23. Vrijlandt EJ, Boezen HM, Gerritsen J, Stremmelaar EF, Duiverman EJ. Respiratory health in prematurely born preschool children with and without bronchopulmonary dysplasia. J Pediatr 2007;150(3): 256-261.

24. Gochicoa-Rangel L, Vargas MH, Alonso-Gómez JL, RodríguezMoreno L, Martínez-Briseño D, Baños-Mejía O, Torre-Bouscoulet L. Respiratory impedance in patients with Duchenne muscular dystrophy. Pediatr Pulmonol 2016;51(10):1072-1079.

25. Sakarya A, Uyan ZS, Baydemir C, Anık Y, Erdem E, Gokdemir Y, et al. Evaluation of children with cystic fibrosis by impulse oscillometry when stable and at exacerbation. Pediatr Pulmonol 2016; 51(11):1151-1158.

26. Bickel S, Popler J, Lesnick B, Eid N. Impulse oscillometry: interpretation and practical applications. Chest 2014;146(3):841-847.

27. Kalliola S, Malmberg LP, Kajosaari M, Mattila PS, Pelkonen AS, Mäkelä MJ. Assessing direct and indirect airway hyperresponsiveness in children using impulse oscillometry. Ann Allergy Asthma Immunol 2014;113(2):166-172.

28. Duiverman EJ, Den Boer JA, Roorda RJ, Rooyackers CM, Valstar M, Kerrebijn KF. Lung function and bronchial responsiveness measured by forced oscillometry after bronchopulmonary dysplasia. Arch Dis Child 1988;63(7):727-732.

29. Clément J, Dumoulin B, Gubbelmans R, Hendriks S, van de Woestijne KP. Reference values of total respiratory resistance and reactance between 4 and $26 \mathrm{~Hz}$ in children and adolescents aged 4-20 years. Bull Eur Physiopathol Respir 1987;23(5):441-448.

30. Aarli BB, Eagan TM, Ellingsen I, Bakke PS, Hardie JA. Reference values for within-breath pulmonary impedance parameters in asymptomatic elderly. Clin Respir J 2013;7(3):245-252.

31. Newbury W, Crockett A, Newbury J. A pilot study to evaluate Australian predictive equations for the impulse oscillometry system. Respirology 2008;13(7):1070-1075.

32. Torre-Bouscoulet L, Pérez-Padilla R, Grupo de Trabajo del Estudio PLATINO en México. [Adjustment of several spirometric reference equations to a population-based sample in Mexico]. Salud Publica Mex 2006;48(6):466-473.

33. Miller MR, Hankinson J, Brusasco V, Burgos F, Casaburi R, Coates A, et al. Standardisation of lung function testing. Eur Respir J 2005;26(2):319-338

This article is approved for Continuing Respiratory Care Education credit. For information and to obtain your CRCE

(free to AARC members) visit

www.rcjournal.com

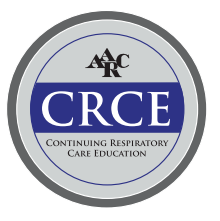

